\title{
Uma análise crítica sobre o empreendedorismo baseado no modelo de negócio de franquias
}

\section{A critical analysis on entrepreneurship based on franchise business model}

\author{
1 Adilson Gustavo do Espirito Santo adilsongustavo@hotmail.com \\ 2 Moacir José dos Santos
}

1 Universidade de Taubaté, UniFOA

2 Universidade de Taubaté

\section{Resumo}

O sistema de franquias cresce no Brasil e representa uma força no mercado nacional. Desde a sua chegada ao país, o modelo de negócios de franquias é associado ao termo empreendedorismo. 0 objetivo principal deste trabalho é realizar uma análise crítica entre a relação do franqueado e franqueador, mostrando os principais problemas que ocasionam o fechamento de unidades franqueadas, tendo como base os anos de 2011 e 2015, época em que o país passou por um crescimento moderado. A metodologia fundamenta-se em pesquisa documental, com os dados coletados, analisados e apresentados de forma estruturada. Os resultados apresentam a influência da economia, fazendo com que indivíduos procurem outra fonte de renda, utilizando, dessa forma, recursos próprios. Entretanto, a necessidade de se obter uma segunda renda, alinhada ao anseio do empresário franqueador em obter mais lucro através de abertura de novas unidades, trouxe problemas para o relacionamento das partes.

\section{Palavras-chave}

Sistema de franchising; franqueado; franqueador.

\begin{abstract}
The franchise system is growing in Brazil and represents a force in the national market. Since its arrival in the country the franchise business model is associated with the term entrepreneurship. The main objective of this work is to perform a critical analysis between the franchisee and the franchisor, showing the main problems that lead to the closure of franchised units, based on the years of 2011 and 2015, when the country experienced moderate growth. The methodology is based on documentary research, with data collected, analyzed and presented in a structured way. The results show the influence of the economy, causing individuals to seek another source of income, thus using their own resources. However, the need to obtain a second income, in line with the desire of the franchisor to gain more profit through the opening of new units, has created problems for the parties' relationship.
\end{abstract}

\section{Keywords}

System of the Franchising; Franchisee; Franchisor;

\section{Como você deve citar?}

SANTO, Adilson Gustavo do Espirito; SANTOS, Moacir José dos. Uma análise crítica sobre o empreendedorismo baseado no modelo de negócio de franquias. Cadernos UniFOA, Volta Redonda, n. 34, p. 47-61, ago. 2017. 
Uma análise crítica sobre o empreendedorismo baseado

no modelo de negócio de franquias

\section{INTRODUÇÃO}

O modelo de franquias foi desenvolvido nos Estados Unidos a partir 1850, por Isaac Singer, e teve a sua entrada no Brasil, a partir de 1950. Segundo a Associação Brasileira de Franchising (ABF), somente a partir da década de 80 é que a franquia se fortaleceu no país, onde tem apresentado altos índices de crescimento.

O sistema de franquias cresce no Brasil e representa uma força no mercado nacional por atrair investidores interessados em adquirir uma autonomia econômica por meio da abertura do próprio negócio.

Devido à ampliação desse ramo, muitas revistas e sites especializados foram criados. Também foram realizados diversos estudos e fóruns que tratam sobre o assunto. Além disso, entidades importantes como o SEBRAE e o FECOMÉRCIO têm dedicado recursos para atuar e trabalhar no ramo.

A relação feita entre franquia e o empreendedor, que passa a ser chamado de franqueado, fica evidente, à medida que novas marcas são criadas ou novas unidades são abertas.

Este trabalho pretende realizar uma análise crítica sobre a relação do franqueado e do franqueador, mostrando os principais problemas que ocasionam o fechamento de unidades franqueadas, além de apontar questões sobre a prática de empresas franqueadoras utilizarem de um método de crescimento em que repassa para o empreendedor as obrigações trabalhistas e tributárias que a franqueadora teria, se fossem abrir lojas próprias.

Também exibirá a evolução das franquias entre os anos de 2011 e 2015, período em que a economia brasileira passou por um crescimento moderado, para avaliar os motivos de sucesso desse crescimento e os possíveis problemas que impactam as unidades.

\section{REFERENCIAL TEÓRICO}

Para realizar a análise crítica sobre o empreendedorismo baseado no modelo de negócio de franquias, este artigo foi estruturado da seguinte forma: na primeira parte, será apresentado o conceito de franquia; na segunda parte, buscar-se-á apresentar a conexão entre franquia e empreendedorismo; na terceira parte, será apresentada a franquia como modelo de mercado no mundo e no Brasil e; na última, serão demonstrados os problemas atuais entre o franqueador e o empreendedor.

\subsection{Conceito de franquias}

No Brasil, o sistema de franquias é regido pela Lei 8.955/94 de Franquia Empresarial, que estabelece o seguinte conceito:

\footnotetext{
Franquia empresarial é o sistema pelo qual um franqueador cede ao franqueado o direito de uso de marca ou patente, associado ao direito de distribuição exclusiva ou semi-exclusiva de produtos ou serviços e, eventualmente, também ao direito de uso de tecnologia de implantação e administração de negócio ou sistema operacional desenvolvido ou detido pelo franqueador, mediante remuneração direta ou indireta, sem que, no entanto, fique caracterizado vínculo empregatício. (BRASIL, Lei 8.955/94)
}

Esse modelo de negócios é composto por duas entidades: o franqueador, que é uma pessoa jurídica que montou inicialmente a empresa, e o franqueado, que pode ser uma pessoa física ou jurídica que recebe a autorização através de contrato, de usufruir o direito de usar a marca criada pelo franqueador. 
Analisando a terminologia da palavra, segundo Bulgarelli (1995, p. 530) franchising deriva do termo inglês franch, que se originou da palavra francesa (dos tempos medievais) franc.

Para o SEBRAE (2016), "o termo Franquia é utilizado tanto para designar o sistema, quanto a pessoa jurídica que participa de uma rede de franquias (a unidade franqueada)."

Outros autores também conceituaram franquia:

Uma franquia é um negócio autorizado a vender os produtos de uma empresa em uma área. 0 franqueador vende o direito de usar seus recursos (por exemplo, o seu nome ou sistema operacional) para uma pessoa ou grupo (franqueado), recebendo em troca uma taxa fixa ou uma participação de seus lucros. (JONES, 2010, p. 67)

Desde a sua chegada ao Brasil, o modelo de negócios de franquias é associado ao termo empreendedorismo, que será abordado na próxima seção.

\subsection{A franquia e o empreendedorismo}

Segundo o SEBRAE (2016), "empreendedor é aquele que inicia algo novo, que vê o que ninguém vê, enfim, aquele que realiza antes, aquele que sai da área do sonho, do desejo, e parte para a ação". Esse conceito definido pelo SEBRAE relaciona o empreendedorismo a mudanças que acontecem no meio empresarial.

Karl Marx (1867) foi o primeiro a comentar sobre a destruição criativa, mas foi em 1942, que o austríaco naturalizado americano Joseph Schumpeter usou esse termo, inserindo-o na perspectiva do negócio, quando escreveu o livro "Capitalismo, Socialismo e Democracia", no qual conceituou "destruição criativa ou destruição criadora". Para Schumpeter (1984), o capitalismo renova os seus produtos, destruindo o velho e criando o novo, dando, com isso, o impulso necessário para o desenvolvimento econômico, que tem como principal agente a figura do empreendedor, que é o grande inovador e, geralmente, traz ao mercado novos produtos ou serviços, criando mudanças nesse mercado ou proporcionando o surgimento de novos mercados.

O empreendedor pode ser definido da seguinte forma:

É uma pessoa criativa e que mantém alta consciência do ambiente em que vive, usando-a para detectar uma oportunidade de negócio. Um empreendedor que continua a aprender a respeito das possíveis oportunidades de negócios e a tomar decisões moderadamente arriscadas, que objetivam a inovação, continuará a desempenhar um papel de empreendedor. Em resumo, empreendedor é uma pessoa que imagina, desenvolve e realiza visões. (FILION, 1999)

O empreendedor busca ser independente para realizar os seus sonhos e, para isso, assume responsabilidades. Assim sendo, pessoas empreendedoras que pensam em abrir uma franquia, em suma, são pessoas que dispõem de certa quantia financeira para realizar o sonho de ser independente e abrir o próprio negócio (SEBRAE, 2016).

Segundo a FENACON (2016), "quatro em cada dez brasileiros já estão envolvidos em abertura de empresas, mas com salto na participação dos que precisam complementar a renda." Também, segundo a FENACON (2016), "houve aumento na participação de pessoas que abriram um negócio próprio por necessidade."

Essa necessidade de abrir um negócio próprio para complementar a renda familiar pode ser para conseguir uma independência do patrão ou por ter um dinheiro para investir, devido ao desemprego ou 
Uma análise crítica sobre o empreendedorismo baseado

no modelo de negócio de franquias

por ter encontrado uma oportunidade de negócio. Para o SEBRAE (2016), a Classe C econômica são os novos empreendedores que saíram da zona de conforto de possuir um emprego formal, para abrir um negócio próprio. De acordo com a pesquisa realizada pelo SEBRAE (2016), 55,5\% dos empreendedores brasileiros faz parte da considerada nova classe econômica média. É importante ressaltar que a classifıcação utilizada pelo SEBRAE é meramente econômica, porque avalia somente o poder de consumo e, por isso, não pode ser usada para classificação de classe social.

A abertura de um negócio próprio não assegura sucesso financeiro. Segundo o relatório de Causa Mortis elaborado pelo SEBRAE (2016), muitas microempresas não passam do segundo ano e o principal motivo para o seu fechamento é a falta de capital ou lucro. Além disso, o relatório também informa que "o fechamento da empresa, ao encerrar um sonho, o desejo de ter o próprio negócio, gera sentimentos negativos no empreendedor, como frustração / perda e tristeza / mágoa."

Essas informações são importantes para avaliarmos como as pessoas são motivadas a abrirem o próprio negócio, mas sem base para administrá-lo. Também, segundo o relatório de Causa Mortis elaborado pelo SEBRAE (2016), "além da frustração e da tristeza, ainda há a perda financeira (mais da metade dos empreendedores perde tudo ou parte do dinheiro investido - dinheiro que é, na maior parte, próprio ou de familiares)."

Para avaliar como que a franquia é vista como uma forma de independência patronal ou para conseguir complemento de renda, o próximo capítulo apresentará a franquia como modelo de mercado e a sua evolução no mercado brasileiro.

\subsection{A franquia como modelo de mercado}

O sistema de franquias é utilizado em quase todos os setores de mercado e teve a sua origem em 1850, época em que Isaac Singer, com o intuito de abrir novos mercados para as suas máquinas de costura, estabeleceu um sistema de franquias. Após isso, outras empresas também passaram a adotar o modelo criado por Singer, como a Kentucky Fried Chicken (KFC), que iniciou o modelo em 1930; a Dunkin Donuts, que iniciou o modelo em 1950; e a mais conhecida de todas, a Mc Donald's, que iniciou o modelo em 1955 (ABF, 2016).

\subsubsection{As franquias no Brasil}

Segundo o SEBRAE (2016), o conceito de franquias chegou ao Brasil em 1954, através de Escolas de Idiomas, como o Yázigi, uma das primeiras franquias de serviços do Brasil, cuja rede teve início em 1954. Entretanto, o modelo somente começou a tomar força a partir de 1979, com a inauguração da primeira loja franqueada do Mc Donald’s e, 1980, com o Boticário. A partir daí, o negócio de franquias tem crescido a passos largos no país.

Segundo Degobbi (2013, p. 13), "no Brasil, o negócio de franquias tem se mostrado atrativo para novos empreendedores, na medida em que sinaliza trajetória crescente. A elevação do consumo propiciada pela "nova classe média" tem gerado bons resultados ao setor."

Segundo Rocha e Gimenez (2011), o percentual de brasileiros que desejam ter um negócio próprio através do modelo de franquias vem aumentando ano a ano, devido à imagem de um negócio seguro, no qual é baseado na marca conhecida no mercado.

Conforme pode ser observado na figura 1, o crescimento de redes franqueadoras vem crescendo anualmente. 
Figura 1 - Evolução das Redes Franqueadoras

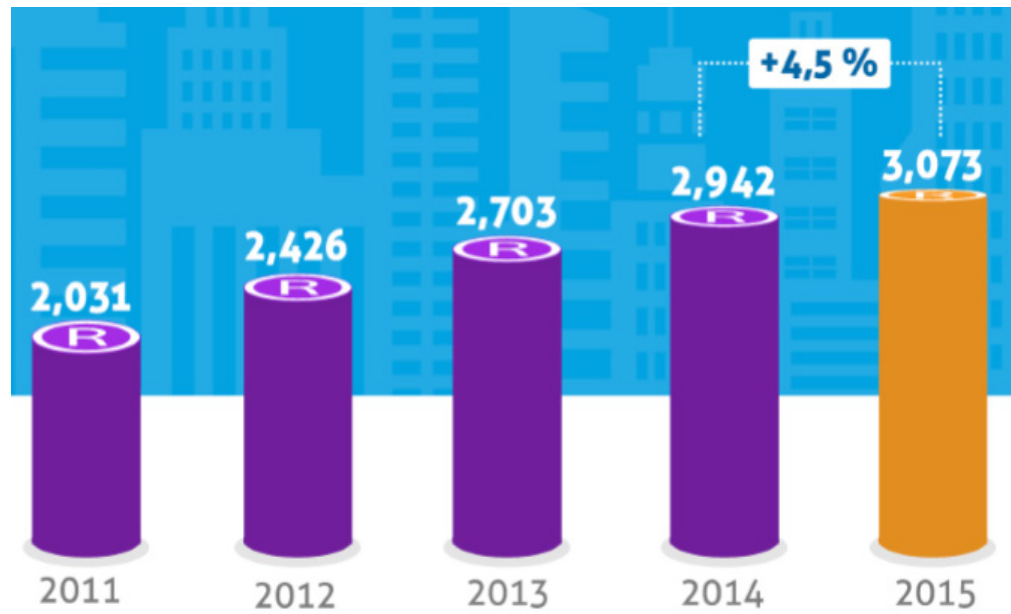

Fonte: Relatório ABF (2016).

Segundo a ABF (2016), 40\% dos municípios nacionais possuem, pelo menos, uma rede de franquia. Isso quer dizer que há operação desse ramo em 2.243 cidades. Nesse cenário, as cidades que mais possuem redes de franquias são São Paulo, com 15,4\%; e Rio de Janeiro, com $6.8 \%$ do número total.

Analisando a projeção para o mercado de franquias em 2016, a ABF apresentou que o faturamento aumentará de $6 \%$ a $8 \%$, enquanto as unidades deverão aumentar de $8 \%$ a $10 \%$. Também informado nessa projeção, a ABF prevê que deverá acontecer um aumento de $4 \%$ a $6 \%$ das marcas de franquias existentes no Brasil. Esses números são excelentes, se for levado em consideração que o Brasil vem passando por uma crise econômica desde 2014.

Conforme pode ser verificado na figura 2, o perfil do brasileiro que mais se enquadra no modelo de franquias é o da região Sudeste, que comporta $71,4 \%$ das redes de franquias nacionais.

Figura 2 - Distribuição das Redes de Franquias no Brasil

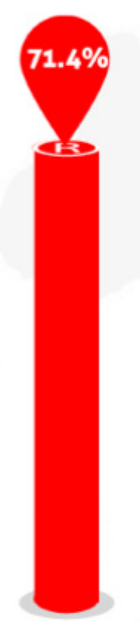

SUDESTE

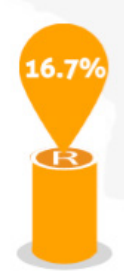

SUL

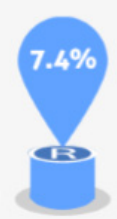

NORDESTE

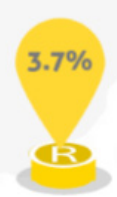

CENTRO

OESTE

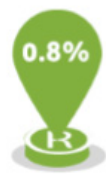

NORTE

Fonte: Relatório ABF (2015). 
Uma análise crítica sobre o empreendedorismo baseado

no modelo de negócio de franquias

A figura acima mostra que as demais regiões do Brasil ainda precisam ter um desenvolvimento maior no setor de franquias. Um dos motivos pode ser o perfil cultural da população que ainda não viu esse ramo como uma forma de negócio seguro e sem riscos ou essas regiões podem não ter avaliado os diversos tipos existentes de franquias. Entretanto, o mesmo gráfico nos leva a refletir por que a região sudeste possui tantas unidades franqueadas.

\subsubsection{Principais tipos de modelos de franquias}

Existem diversos tipos de franquias. 0 empreendedor pode optar escolhendo a que melhor atende as suas necessidades, levando em consideração o local onde pretende atuar e o mercado que deseja atender.

Segundo o SEBRAE (2016), os principais tipos de franquia no Brasil são:

a. Franquia unitária: cessão de direito de abertura de uma unidade, com exclusividade de atuação em local determinado pelo franqueador. Exemplo: uma loja ou quiosque em um determinado Shopping Center. 0 mesmo franqueado pode adquirir outras franquias unitárias, dependendo de sua capacidade financeira, desempenho alcançado e plano de expansão do franqueador.

b. Franquia Master. modelo comumente utilizado nos planos de internacionalização de franquias e em países de grandes dimensões geográficas, como o Brasil. O Master Franqueado (ou Subfranqueador) assina um contrato que lhe dá o direito de implantar ou terceirizar outras unidades franqueadas em uma determinada região. Nesse caso, os contratos serão assinados pelo Master Franqueado e ele receberá parte do valor da taxa de franquia e dos royalties cobrados dos franqueados, responsabilizando-se pelo treinamento e suporte a eles.

c. Franquia de Desenvolvimento de Área: cessão de direito para exploração de uma determinada região, onde o franqueado abrirá mais de uma unidade em um determinado espaço de tempo. Será firmado um contrato para o desenvolvimento da área e para cada unidade que ele abrir. 0 desenvolvedor de área também poderá vender unidades em sua região, recebendo parte do valor cobrado a título de taxa de franquia e royalties. Todos os contratos são firmados com o franqueador.

d. Microfranquias: são caracterizadas por exigirem um baixo investimento inicial de até R\$ 80 mil, terem um baixo custo operacional e uma operação simplificada, em atividades que podem ser realizadas pelo próprio franqueado e, muitas vezes, sem exigência de um ponto comercial. Geralmente o franqueado pode operá-la de sua própria residência ou se deslocar até o endereço do cliente para atendê-lo, sendo, nesses casos, chamadas de home based.

Alem disso, segundo o FranquiaeCia (2016), existem também os tipos:

a. Franquia shop in Shop: quando o empresário já possui ponto comercial e deseja colocar uma franquia de ramo diferente no mesmo local, para ter um aproveitamento melhor do seu ponto comercial, alavancando o negócio existente e criando uma nova fonte de renda sem um investimento muito alto.

b. Franquia combinada: quando o franqueado já possui uma franquia e deseja incorporar outra no mesmo estabelecimento. 
Todos esses tipos de franquias precisam ser analisados pelo empreendedor antes de se fechar um contrato.

Segundo Mauro (2007), quando se usa o modelo de franquia como canal de distribuição, é importante verificar o mercado onde a franquia atuará, qual o perfil do consumidor, qual o melhor sistema de compras e realizar os estudos de viabilidade financeira.

0 empreendedor adota o modelo de franquia porque o identifica como um redutor dos riscos de fracasso, no qual se baseia que é um modelo homologado e suportado por uma marca, além de já ter um conhecimento prévio do pessoal de suporte técnico e por já possuir uma gestão estruturada (ROCHA e GIMENEZ, 2011).

Segundo Rocha e Gimenez (2011), existem três tipos de perfis de franqueados:

\begin{abstract}
O perfil empregado busca atingir suas metas e objetivos, através do cumprimento estrito das regras da franquia, já o perfil empresário também busca segui-las, porém coloca mais peso nas metas de sua unidade. Tem mais facilidade de estabelecer trade-offs (alternância de objetivos), sabendo quando sacrificar determinado objetivo, a fim de favorecer a outro mais importante para a estratégia de seu negócio. 0 perfil empreendedor também se mostra seguidor de regras, pois entende que é a forma inicial, para fortalecer seu negócio. No entanto, mostra ambição de crescimento, tem foco na gestão e gosta de ver suas ideias realizadas (ROCHA e GIMENEZ, 2011).
\end{abstract}

De acordo com Rocha e Gimenez (2011), o perfil do empresário é o que possui um melhor relacionamento com o franqueador, porque procura ser mais disciplinado com as regras de negócios e tem uma postura menos crítica.

O mercado brasileiro suporta cada tipo de franquia descrito acima que estão inseridos em quase todos os setores de mercado. A Figura 3 apresenta como o modelo de franquia está distribuído no mercado brasileiro.

Figura 3 - Participação dos Segmentos de Mercado por número de unidades

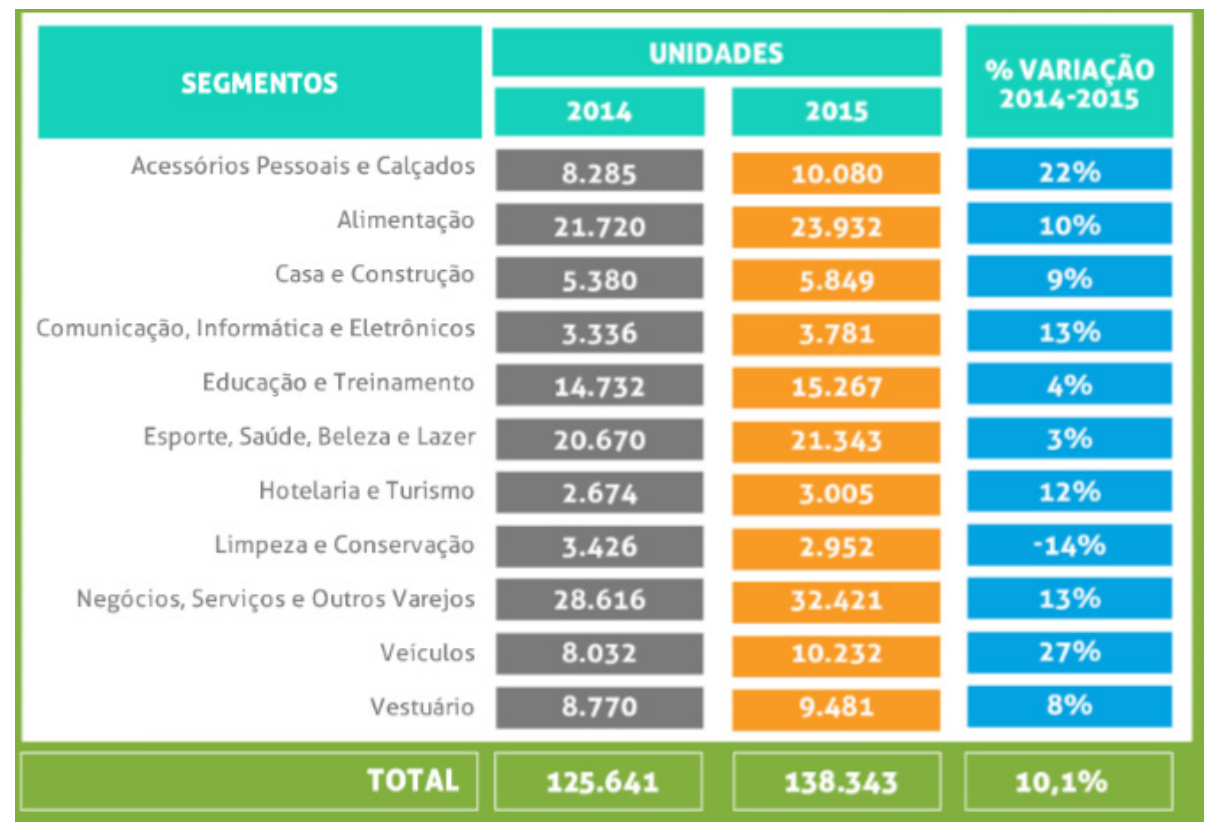

Fonte: Relatório ABF (2016). 
Uma análise crítica sobre o empreendedorismo baseado

no modelo de negócio de franquias

Conforme demonstrado na figura 3, o modelo de franquias está em quase todos os segmentos de mercado e também é possível verificar que houve um crescimento de 10,1\%, de 2014 para 2015, em unidades instaladas. Além dos resultados desses anos, segundo a ABF (2016), em 2011, o Brasil possuía 93.098 unidades instaladas; em 2012, 104.543 unidades e; em 2013, 114.409 unidades . Esse aumento também acontece devido à chegada das microfranquias no mercado brasileiro. A visão de iniciar o próprio negócio a um custo baixo tem atraído cada vez mais pessoas e, segundo a revista Exame (2016), para esse tipo de franquia, em 2012, havia 32 marcas e, em janeiro de 2016, 56 marcas.

Ao mesmo tempo em que existe o crescimento das marcas de microfranquias, a quantidade de unidades fechadas também cresce. De acordo com a revista Exame (2016), "quando avaliamos essas redes pela média de unidades por franqueadora os números aparecem de ordem inversa. Crescem demasiadamente as novas franqueadoras e a quantidade de unidades franqueadas começa a cair na mesma proporção." Isso passa a ser um problema sério, porque essas redes começam a fechar mais do que abrem, não conseguindo consolidar seus modelos. E o empreendedor sofre não só por fechar a unidade, junte-se a isso a perda do sonho de ter o próprio negócio e o dinheiro investido.

0 modelo de franquias é baseado na concessão de marca que o franqueador fornece para utilização do empreendedor, sendo que essa concessão é firmada entre as partes por meio de um contrato.

\subsubsection{Teoria dos contratos e o modelo de franquias}

É comum que algumas necessidades pessoais, empresariais ou organizacionais sejam realizadas através de outras pessoas, empresas ou organizações e, para isso, utiliza-se a prática da contratação. Segundo Heinze (2005, p. 3), "uma relação de contratação pode ser interpretada como uma relação entre agente e principal, no qual o principal contrata um agente para realizar uma ação." Essa contratação é celebrada por meio de um contrato, que é um documento que possui as regras, objetivos da ação e formalidades de pagamento, no qual o principal pode ou não ter total controle da execução da ação, dependendo das regras baseadas no contrato.

Nos parâmetros de franquia, o agente, além de ser o executor da ação, realiza o retorno financeiro para o principal, que, nesse caso, é o Franqueador. Os dois celebram um modelo de contrato, no qual o principal cede para o agente o seu modelo de negócio para que possa usufruir, gerar lucro e repassar a parte do franqueador.

Segundo Vance (2010, p. 5), "ao mesmo tempo em que o contrato limita a liberdade de ação do franqueado, estabelece uma interdependência na remuneração de ambas as partes ao longo da vigência de todo o contrato"

Ainda de acordo com Vance (2010, p. 5), "a remuneração do franqueador, seja baseada na cobrança de royalties ou pela venda de produtos, depende do desempenho do franqueado" Nessa parte, podemos verificar que, por força de contrato, o franqueado é quem está na linha de frente das vendas e que todo o esforço será transformado em sucesso ou fracasso.

Apesar de o franqueador dar o apoio logístico e de marketing, é o franqueado quem realmente faz o negócio funcionar. Também segundo Vance (2010),

em geral, os contratos prevêem pouca autonomia de gestão para o franqueado. Por exemplo, em algumas redes, é definido o mix mínimo de produtos que a loja deve comprar. Em outros, o preço ao consumidor de todos ou de vários itens pode ser definidor pelo franqueador (VANCE, 2010, p. 4). 
Essa falta de autonomia do franqueado também é citada por Schwartz, quando observa as principais obrigações do franqueador:

\begin{abstract}
a) representar o seu sistema de negócios junto ao mercado, associações de classe, poderes públicos e demais órgãos ou entidades, com o objetivo de manter a unidade corporativa da franquia; b) conceder os direitos de uso da sua marca e do sistema sempre através de contrato escrito; c) observar a exclusividade territorial em favor do franqueado; d) assessorar o franqueado na construção e instalação do ponto comercial, fornecendo, para tanto, a título gratuito ou não, projetos e especificações gerais; e) prestar assistência inicial e contínua ao franqueado e ao pessoal por ele contratado, através de cursos e treinamentos, suportando os custos ou rateando-os com o franqueado, na forma contratualmente estabelecida; f) assegurar ao franqueado a transmissão permanente do know-how; g) promover a marca, o produto ou o serviço, sem custo ao franqueado ou em conjunto com este, rateando os custos em bases previamente acordadas; $h$ ) fornecer ou orientar o abastecimento contínuo e adequado de produtos acabados ou necessários à franquia, nos termos estabelecidos no contrato; i) acatar e subordinar-se às leis vigentes e ao Código de Auto-Regulamentação da Associação Brasileira de Franchising (SCHWARTZ, 2003, p. 27).
\end{abstract}

As observações acima deixam claro que existe um modelo de hierarquia entre franqueador e franqueado, que é obrigado a ser seguido por força de contrato. Esse modelo é praticamente parecido como a relação entre patrão e empregado. Segundo Rubin (1978, p. 232), "o franqueado está mais próximo de ser um empregado do franqueador do que um empreendedor independente."

\title{
3 METODOLOGIA
}

O estudo realizou um levantamento dos dados técnicos referentes aos anos de 2011 a 2015. Além disso, buscou-se levantar o espaço da franquia no Brasil. Quanto à metodologia, trata-se de uma pesquisa descritiva, pois apresenta o mercado brasileiro em relação a franquias, com análise crítica entre o franqueado e franqueador. Buscou-se também realizar o levantamento bibliográfico sobre o tema.

Os dados foram coletados em livros, revistas especializadas, artigos científicos, artigos em jornal, tese e dissertações e dados disponibilizados na internet, compreendendo-se os anos de 2011 a 2015, período utilizado no relatório da ABF (2016).

Os dados foram tratados de forma qualitativa, pois se trata de um levantamento bibliográfico, no qual os dados coletados foram codificados, analisados e apresentados de forma estruturada.

\subsection{Limitação do método}

Esta pesquisa foi ancorada basicamente em dados secundários que servem somente como orientação para futuros estudos mais detalhados. Apesar de não ter sido realizada a pesquisa de campo, o estudo utilizou dados apontados em pesquisas de campo de teses e dissertações aqui citadas.

\section{RESULTADOS E DISCUSSÃO}

\subsection{Relação franqueador $e$ franqueado}

Para realizar a análise crítica sobre o empreendedorismo baseado no modelo de negócio de franquias é preciso avaliar também a relação que acontece entre o franqueador e o franqueado, de forma a demonstrar quais problemas ocorrem nesse tipo de relacionamento.

Conforme apresentado nos capítulos anteriores, a relação entre franqueador e franqueado possui problemas, devido ao modelo de franquia e o tipo de contrato formado entre as partes. 
Segundo Degobbi (2013, p 15), "o franqueado tem atributos que interessam ao franqueador e este, por sua vez, tem ativos relevantes como o valor da marca e o conhecimento da gestão do negócio. Nesse tipo de relação, é de se esperar o surgimento de conflitos, devido a interesses diferenciados entre os indivíduos." Nessa observação realizada, pode-se entender porque existem tantos conflitos entre Franqueador e Franqueado.

Ainda de acordo com Degobbi (2013, p 16), "esta possibilidade de atritos no relacionamento pode afetar a governança do negócio e agravar o nível de aversão aos riscos de cada uma das partes."

As obrigações do franqueado são as seguintes:

\begin{abstract}
a) promover a remuneração, estabelecida em contrato, ao franqueador; b) prestar os serviços, conforme as estipulações contratuais; c) exercer o objeto da franquia, de forma a proteger, divulgar e promover a marca do franqueado; c) suportar os custos relativos ao contrato de franquia, constituindo, para tanto, firma que possa remunerar o franqueador da forma previamente estabelecida no contrato; d) observar, no momento da implantação da franquia, os aspectos referentes ao imóvel onde esta será explorada, obedecendo os padrões estabelecidos pelo fornecedor, não realizando mudanças na apresentação do negócio, sem a prévia autorização do franqueador; e) obedecer, rigorosamente, as especificações do franqueador quanto aos produtos, serviços ou uso da marca; f) não quebrar o sigilo referente aos métodos, técnicas e processos utilizados pelo franqueador na elaboração de seus produtos; g) não envolver o franqueador em obrigações e operações de crédito não reguladas expressamente pelo contrato; e, h) obedecer às estipulações do Código de Auto-Regulamentação da ABF e às inerentes ao contrato celebrado com o franqueados (ARAÚJO; WINKING, 2012, p. 04).
\end{abstract}

Analisando melhor as suas obrigações, fica claro que o franqueado acaba tendo mais a função de um gerente do que a função de um administrador do negócio, e a relação entre as partes acaba sendo mais um tipo de abertura de uma filial que responde a uma matriz. Em alguns tipos de contrato, caso a gestão do franqueado seja ruim, a franqueadora assume, por força de cláusula contratual, a gestão do negócio no lugar do franqueado.

Esse tipo de visão fica muito claro no artigo $2^{\circ}$ da lei $8.955 / 94$, no qual se registra:

\begin{abstract}
"Art. $2^{\circ}$ Franquia empresarial é o sistema pelo qual um franqueador cede ao franqueado o direito de uso de marca ou patente, associado ao direito de distribuição exclusiva ou semiexclusiva de produtos ou serviços e, eventualmente, também ao direito de uso de tecnologia de implantação e administração de negócio ou sistema operacional desenvolvidos ou detidos pelo franqueador, mediante remuneração direta ou indireta, sem que, no entanto, fique caracterizado vínculo empregatício." (BRASIL, Lei 8.955/94),
\end{abstract}

Conforme observado acima, a inclusão do texto "sem que, no entanto, fique caracterizado vínculo empregatício", se fez necessário, devido ao fato de que, em alguns casos, o modelo de trabalho pode ser caracterizado como vínculo empregatício. Para Souza (2012), a expansão do ideal de empreendedorismo corresponde a uma exteriorização dos custos das grandes empresas e também à reorganização do trabalho, em que a empresa, ao invés de abrir novas unidades e contratar funcionários, observa que se torna mais viável repassar esses custos para as unidades franqueadas.

Há de se verificar melhor quais as vantagens e desvantagens em se obter uma franquia. De certo modo, existirá nesse modelo de contrato uma estratégia de cooperação, para que ambas as partes possam sobreviver e obter retorno financeiro satisfatório.

Uma estratégia de cooperação é uma estratégia em que as empresas trabalham juntas para atingir um objetivo comum. Assim, cooperar com outras empresas é mais uma estratégia usada para criar valor para um cliente que vai além do custo de oferecer esse valor e para estabelecer uma posição favorável em relação aos concorrentes. (HITTI, IRELAND E HOSKISSON, 2001, p. 246).

Segundo Pereira (2013), as principais vantagens do modelo de franquia, para ambas as partes, são: 
Quadro 1 - Possíveis vantagens do sistema de franquias para o franqueador e franqueado.

\begin{tabular}{|l|l|}
\hline FRANQUEADOR & FRANQUEADO \\
\hline Rapidez na expansão. & Maior chance de sucesso. \\
\hline Redução de custos. & Marca conhecida. \\
\hline Maior motivação. & Facilidade na instalação. \\
\hline Aumento da rentabilidade. & Propaganda e marketing cooperados. \\
\hline Cobertura geográfica maior. & Pesquisa e desenvolvimento. \\
\hline Fortalecimento da marca. & Independência do negócio. \\
\hline Melhores representantes. & Maior lucratividade. \\
\hline Redução de problemas trabalhistas. & Maior garantia de mercado. \\
\hline
\end{tabular}

Fonte: Pereira (2013), Adaptado de (IGF, 2007), Maemura (2009) e Vance (2010).

Analisando o Quadro 1, verificamos que ambas as partes obtêm vantagens que potencializam o modelo de negócio. Também é possível verificar que novamente aparece como vantagem para o franqueador a redução de problemas trabalhistas.

Também segundo Pereira (2013), as principais desvantagens do modelo de franquia, para ambas as partes, são:

Quadro 2 - Desvantagens do sistema de franquias para o franqueador e franqueado.

\begin{tabular}{|l|l|}
\hline FRANQUEADOR & FRANQUEADO \\
\hline Perda parcial do controle. & Localização forçada. \\
\hline Divisões da receita. & Autonomia parcial. \\
\hline Retorno a prazos mais longos. & Seleção ineficiente. \\
\hline Risco de desistência. & Risco vinculado ao desempenho do franqueador. \\
\hline Perda de sigilo. & Restrições na cessão do sistema. \\
\hline Expansão sem planejamento. & Maiores controles. \\
\hline Seleção inadequada. & $\begin{array}{l}\text { Limitações na escolha de produtos e de } \\
\text { fornecedores. }\end{array}$ \\
\hline Perda de padronização. & Risco vinculado à imagem da marca. \\
\hline $\begin{array}{l}\text { Maiores custos de formatação e de } \\
\text { supervisão. }\end{array}$ & Risco de descumprimento do contrato. \\
\hline
\end{tabular}

Fonte: Pereira (2013), Adaptado de IGF (2007) e Maemura (2009).

No Quadro 2, verificamos que existem grandes desvantagens para ambas as partes. Também é possível verificar que o franqueado possui restrições maiores, devido ao modelo engessado de contrato que ele deve seguir.

Um dos principais fatores de sucesso para uma franquia é que, muitas vezes, o franqueado reside no território de sua unidade, podendo ter conhecimento e acesso ao mercado local, superior ao do franqueador. Além disso, ter o dono da loja à frente do negócio é uma garantia maior para o franqueador (DEGOBBI, 2013, p. 15).

Também seguindo essa visão, segundo Pereira (2013, p. 8), "o fato dos franqueados não serem funcionários do franqueador e sim empresários independentes, os posiciona pessoalmente interessados no sucesso do negócio." Em consonância com essa observação, para Elango e Fried (1997), proprietários são mais motivados para atingir resultados do que gerentes de uma estrutura tradicional. 
Uma análise crítica sobre o empreendedorismo baseado

no modelo de negócio de franquias

Apesar disso, o relacionamento entre franqueador e franqueado passa a mudar com o passar o tempo.

Existe um ciclo de vida, dividido em três fases, que correspondem à satisfação do franqueado: a primeira fase consiste no entusiasmo pelo sistema, ocorre no início do relacionamento, quando o franqueado está recebendo os treinamentos, com o franqueado sendo novo na rede, tem muito que aprender; a segunda fase é quando a satisfação atinge o seu grau mais baixo, no momento em que o franqueado torna-se competente no sistema, sentindo-se mais seguro o franqueado começa a questionar o franqueador; enfim a terceira fase se transforma na aceitação do sistema, onde o franqueador contribui para aumentar o comprometimento do franqueado, fortalecendo a relação entre ambos, adotando sistemas de coordenação e adaptação que estimulem a congruência de metas entre as partes. (PEREIRA, 2013, p. 8)

O problema centrado na segunda e terceira fases citado acima, é o aumento de conflitos que acontecerá no relacionamento, uma vez que o franqueado passa a querer mais do que o contrato permite. Apesar disso, o autor também informa que

os conflitos se bem resolvidos, fazem o sistema crescer, pois a partir dos conflitos podem ocorrer novas ideias interessantes para o negócio, transformando o que era um ponto negativo em um ponto positivo. Entretanto, o conflito em excesso pode prejudicar a rede, de qualquer forma, a identificação de pontos de divergência e de baixa satisfação não parece comprometer a expansão do franchising. (PEREIRA, 2013, p. 9)

Nessa questão de conflitos, segundo a PEGN (2016), para entrar no sistema de franquias, o franqueado precisa estar disposto a se relacionar com o franqueador e também com outros franqueados da mesma rede, com os seus clientes e com os seus fornecedores, pois se essa comunicação não for bem realizada ou se o franqueador não cumprir o prometido, o relacionamento e, consequentemente, a franquia tende a acabar. Para a revista, "o que pode acontecer é o franqueado não estar satisfeito com a marca, não gostar do franqueador, que, por sua vez, não escuta o franqueado. Problemas de opinião ocasionam um racha" (PEGN, 2016).

De acordo com Pereira (2013, p. 23), "os principais conflitos existentes entre franqueador e franqueado são relacionados à padronização das redes, ao desacordo com fornecedores, à elaboração de seus contratos e à deficiência na comunicação entre as partes."

Segundo a PEGN (2016), "a taxa de mortalidade de franquias é de 3,7\%. Em negócios independentes, essa taxa chega a $24 \%$, segundo dados do SEBRAE. Mesmo com números baixos, é preciso haver cuidado antes de escolher uma franquia para o negócio não fracassar."

\section{CONCLUSÃO}

O modelo de franquias vem crescendo no Brasil e representando uma força no mercado nacional que atrai cada vez mais pessoas interessadas em abrir o seu próprio negócio. 0 crescimento desse setor foi de, aproximadamente, 49\% sobre unidades abertas, entre os anos de 2011 a 2015, período em que o Brasil iniciou um período de recessão. Essas duas informações estão relacionadas diretamente, visto que a recessão fez com que as empresas diminuíssem o seu quadro de funcionários, o que motivou pessoas a utilizarem seus recursos financeiros para conseguir abrir o próprio negócio através de franquias.

A vontade de possui um negócio próprio, alinhada à necessidade do empresário franqueador em aumentar seu lucro através de abertura de novas unidades não trouxe somente benefícios, mas também problemas para o relacionamento das partes. 
Este estudo verificou que o empreendedor, ao acreditar que a compra de uma franquia diminui os riscos de aceitação do produto no mercado como também o tempo de retorno financeiro, percebe tardiamente que, em alguns casos, existem cláusulas contratuais que o impede de gerir o próprio negócio de forma independente. Análise de mercado, perfil de clientes, padronização, marketing, mix de produtos estão condicionados a cláusulas que o empreendedor deve seguir, independente do resultado do negócio. Além disso, o empreendedor também pode ter problemas de aceitação de mercado de um produto ou serviço que ainda não está fortemente consolidado. Quando esses problemas não são resolvidos, o empreendedor fica com a única opção de fechar o empreendimento.

É necessário que sejam realizados estudos para avaliar o impacto que o fechamento de unidade franqueada traz para o empreendedor, visto que ele acaba utilizando recursos próprios para abrir a empresa e, com isso, o fechamento da unidade acaba sendo também a perda do capital familiar. 
Uma análise crítica sobre o empreendedorismo baseado

no modelo de negócio de franquias

\section{REFERÊNCIAS}

ABF. Associação Brasileira de Franchising. Números do Franchising. Disponível em: <http://www.abf. com.br/numeros-do-franchising/>. Acesso em: 20 jul. 2016.

ARAÚJO, Simone do A. F.; WINKING, Raíssa H. Franchising e suas implicações no mercado econômico brasileiro. Jus Navigandi, Teresina, ano 17, n. 3463, 24 dez. 2012. Disponível em: <http://jus.com.br/ revista/texto/23297>. Acesso em: 20 de jul. 2016.

BRASIL. Lei ${ }^{\circ}$ 8.955, de 15 de dezembro de 1994. Dispõe sobre o contrato de franquia empresarial (franchising) e dá outras providências. Diário Oficial da república Federativa do Brasil. Brasília, DF, 5 de dezembro de 1994. Disponível em: <http://www.planalto.gov.br/ccivil_03/leis//8955.htm>. Acesso em: 20 jul. 2016.

BERNARD, D. A. Como escolher a franquia certa: as melhores práticas. São Paulo: Atlas, 2000.

BULGARELLI, Waldírio. Sociedades comerciais. 7. ed. São Paulo: Saraiva, 1998.

Contratos mercantis. 8. ed. São Paulo: Atlas, 1995.

COMBS, J. G.; KETCHEN, D. J. J. Can capital scarcity help agency theory explain franchising? Revisiting the capital scarcity hypothesis. Academy of Management Journal, v.42, n. 2, p.196-207, 1999.

DEGOBBI, Antonio Fernando. A percepção do franqueado às interações formais e informais com o franqueador. um estudo exploratório na região de Osasco. 2013. 94 p. (Mestrado em administração) Faculdade Campo Limpo Paulista, Campo Limpo Paulista, 2013.

ELANGO, B.; FRIED, V.H. Franchising research: A literature review and synthesis. Journal of Small Business Management, v. 35, n. 3, p. 68-81,1997.

EXAME. Conheça os riscos de investir numa microfranquia. Disponível em: <http://exame.abril.com.br/ pme/noticias/9-passos-para-aprender>. Acesso em: 24 jul. 2016.

FENACON. Empreendedores por necessidade. Disponível em <http://www.fenacon.org.br/noticias/ empreendedores-por-necessidade-325/>. Acesso em: 22 jul. 2016.

FILION, L. J. Empreendedorismo: empreendedores e proprietários-gerentes de pequenos negócios. Revista de Administração da Universidade de São Paulo, v.34, n.2, p.5-28, 1999.

FRANQUIAECIA. Tipos de franquias. Disponível em: $<$ http://franquiaecia.com/2015/09/30/tipos-defranquias/>. Acesso em: 22 jul. 2016.

HEINZE, F. G. Determinantes de esquemas de pagamentos em contratos de franquias. São Paulo: FGV 2005. 53p. Dissertação de mestrado apresentada ao programa de pós-graduação Mestrado Profissional em Finanças e Economia da Fundação Getúlio Vargas.

HITT, M. A.; IRELAND, R. D.; HOSKISSON, R. E. Administração estratégica: competitividade e globalização. 2. ed. São Paulo: Thomson Learning, 2008.

JONES, G. R., Teoria das Organizações. 6. ed. São Paulo: Nobel, 2010. 
MAURO, P.C. Guia do franqueado. São Paulo: Nobel, 2007.

PEREIRA, LUANA TORASSI. Um estudo sobre o relacionamento entre franquedor e franqueado nas empresas de franquias do município de Criciúma, SC. 2013. 25 p. (Curso de Administração de Empresas) - Universidade do Extremo Sul Catarinense, Criciúma, 2013.

PEGN. Revista Pequenas Empresas \& Grandes Negócios. Disponível em: < http://revistapegn.globo.com/ Franquias/noticia/2015/03/4-erros-que-sao-fatais-para-franquias.html> . Acesso em: 23 jul. 2016.

SCHWARTZ, José Castro. Franquia de A a Z: o que você precisa saber. Rio de Janeiro: Editora Qualitymark, 2003.

SCHUMPETER, Joseph Alois. Capitalismo, socialismo e democracia. Rio de janeiro: Zahar Editores, 1984.

ROCHA, F. B.; GIMENEZ, F. A. P. Impacto da Postura do Comportamento do Franqueado e de sua Relação com o Franqueador no Desempenho da Franquia. Anais do Encontro Nacional da Associação Nacional de Pós-graduação e Pesquisa em Administração, Rio de Janeiro, RJ, Brasil, 2011.

RUBIN, P. The Theory of the firm and Structure of the franchise contract. Journal of Law and Economics. v. 21, n.1, p. 223-233, 1978.

SEBRAE. Relatório Sebrae de Franquias. Disponível em < http://www.sebrae.com.br/Sebrae/Portal\%20 Sebrae/Anexos/franquias_portal_sebrae.pdf>. Acesso em: 21 jul. 2016.

SEBRAE. O Que É Ser Empreendedor. Disponível em <http://www.sebrae.com.br/sites/PortalSebrae/ bis/o-que-e-ser-empreendedor,ad17080a3e107410VgnVCM1000003b74010aRCRD>. Acesso em: 21 jul. 2016.

SEBRAE. Tipos de Franquia. Disponível em <http://www.sebrae.com.br/sites/PortalSebrae/artigos/ conheca-os-tipos-de-franquias,98bb39407feb3410VgnVCM1000003b74010aRCRD>. Acesso em: 22 jul. 2016.

SEBRAE. Relatório Causa Mortis. Disponível em <http://www.sebraesp.com.br/arquivos_site/biblioteca/ EstudosPesquisas/mortalidade/causa_mortis_2014.pdf>. Acesso em: 21 jul. 2016.

SOUZA, Jessé de. Os batalhadores brasileiros: nova classe média ou nova classe trabalhadora. 2. ed. Belo Horizonte: Editora UFMG, 2012.

VANCE, Patrícia de Salles. Determinantes e dinâmica do uso de formas plurais em redes de franquia. 2010. 245 p. (Doutorado em Administração) - Faculdade de Economia, Administração e Contabilidade, Universidade de São Paulo, São Paulo, 2010. 